\title{
Determination of Static and Fatigue Characteristics of Carbon Fiber Reinforced Polyester Composites for Automobile Applications
}

\author{
Velusamy Mugesh Raja ${ }^{a}$, Sekaran Sathees Kumar ${ }^{b *}$ (i) \\ ${ }^{a}$ University college of Engineering, Department of Mechanical Engineering, Ramanathapuram, \\ Tamilnadu, India \\ ${ }^{b}$ CMR Institute of Technology, Department of Mechanical Engineering, Hyderabad, Telangana, India.
}

Received: August 8, 2019; Revised: November 8, 2019; Accepted: December 19, 2019

In this research, suspension through carbon fiber reinforced polyester fiber has given importance because of its adaptability. Leaf springs were moulded the usage of $20 \%$ short carbon fiber reinforced polyester (SF), 20\% length carbon fiber reinforced polyester (LF) as well as Unreinforced polyester (UP) are evaluated for the joint strength. For determining energy storage, capability and strain rate sensitiveness of moulded leaf spring static overall performance assessments had been completed. Check joints had been subjected to absolutely reversed fatigue loads, at fixed frequency fatigue; leaf spring performance changed into evaluated, with diverse loads until $2 \times 10^{7}$ cycles. The tensile surface failure morphology of the cracks has exhibited via the Scanning Electron Microscope (SEM). The results confirmed the suitability of carbon fiber reinforced polyester fiber for load utility over other taken into consideration materials.

Keywords: Fatigue, long fiber, thermoplastic, SFPE, SEM, UPFE.

\section{Introduction}

A leaf spring is the primary issue commonly used for suspension in every wheeled car. Leaf springs are used in motors to isolate shocks and vibrations transmitted because of the choppy street situations. due to the superior performance of particular pressure power, damping and corrosion resistance of composite materials over metal, Composite leaf springs had been being broadly utilized in light weight vehicles, passenger cars, heavy tank trailer suspension structures and in vibrating machineries ${ }^{1-5}$ because of the advanced overall performance of precise stress energy, damping and corrosion resistance of composite materials over steel.various sizes and styles of leaf springs may be produced via compression moulding; but, the mass manufacturing functionality ${ }^{6}$ is constrained with the aid of production time concerned in compression moulding. The mass production functions of composite leaf springs ${ }^{7}$ are limited by using hand lay-up vacuum bag procedure entails a high degree of abilities for blending and manage of resin contents. as soon as, the fabrication of composite leaf spring synthetic with the aid of the usage of Epoxy, Polyester and Polyimide resins. For the reinforcement of leaf springs, unidirectional E-glass, S-glass and carbon fiber had been used. The advanced capability for industrial leaf spring programs over S-glass and carbon fiber presents by way of the finest combination of value and overall performance of E-glass fiber. within the matrix resins, epoxy resins based totally on cost and ease of system capacity ${ }^{8}$ was dominated through polyester.

In quick, the fundamental limitations of thermoset composite leaf springs are having the constrained manufacturing functionality. Discontinuous lengthy fiber

*e-mail: shrutishyami@gmail.com reinforced thermoplastics have uncovered important function in replacing metals, short fiber reinforced thermoplastics, thermoset sheet moulding and bulk molding composites

${ }^{9}$ because of the big manufacturing requirement in the car industries. the manufacturing method of short fiber reinforced thermoplastics and long fiber reinforced thermoplastics is completely distinctive from every different. Extrusion method has used within the manufacture of brief fiber strengthened thermoplastic pellets in which fiber internal pellets is arbitrarily orientated. but fiber became well aligned inside the pellets of lengthy fiber strengthened thermoplastics due to the pultrusion approach. To raise the modulus and strength of the material as high as $90 \%$ of that obtained when using continuous fiber , increased length and fiber orientation inside pellets are serving efficiently. To elevate the modulus and electricity of the cloth as excessive as $90 \%$ of that obtained when the use of continuous fiber ${ }^{10}$, accelerated length and fiber orientation interior pellets are serving efficiently. Zhang et al. ${ }^{11}$ confirmed that longer fiber composite possessed higher resistance than shorter fiber thermoset composites via his research over the effect of fiber duration on tribological houses of quick carbon fiber reinforced epoxy composites. Mathew et al. ${ }^{12}$ done put on exams on a reciprocating sliding check rig with ball-onplate configuration for 4 sorts of directionally oriented warp knit glass plays with polyester, vinyl ester and epoxy resin and stated the enhanced put on resistance of epoxy resin in comparison to counterparts. Mathew et al. ${ }^{13}$ found the quality composite based on the association of interlacement with the aid of his examine over the effect of sliding frequency on the reciprocating sliding wear behaviour of 3D-ply woven interlocked systems with various interlacement for nylon fiber /polyester resin composites. in advance investigation ${ }^{14,15}$, 
stated design and development elements of thermoset leaf springs, however, due to intricacy concerned in fabricating thermoset leaf springs; the manufacturing capability is exceptionally confined.

Consequently, an strive is made with discontinuous glass fiber strengthened carbon fiber by using injection moulding the leaf spring and its preliminary performance characteristic is said somewhere else ${ }^{16}$ past investigations ${ }^{17-28}$ centered the bolted joint power performance and failure mechanisms of continuous fiber thermosets and thermoplastics. In this experiment, the static and dynamic performance of the injection moulded unreinforced, quick, lengthy glass fiber reinforced polyester composite leaf spring joints are evaluated. Effect of reinforced fiber period over static performances, fatigue characteristics and tensile failure morphologies of the springs have been tested.

\section{Materials and Manufacturing Methods}

\subsection{Materials}

Leaf springs are injection molded from 20\% short carbon fiber reinforced polyester (SF), 20\% long carbon fiber reinforced polyester (LF), and unreinforced polyester (UP). Composition and mechanical properties of the selected fabric are indexed in Table $1^{29}$. SF pellets are organized in which fibers are arbitrarily oriented. and LF pellets had been organized from pultrusion technique in which fibers are properly oriented at the side of the pellet duration. Pellets become obtained from Supreme Scientific fibres, Coimbatore, Tamil Nadu India, in keeping with the product information sheet, same molecular weight changed into being possessed via the base resin polyester and coupling agent having equal amount of silane kind turned into used for the carbon fibers in LF and SF.

\subsection{Manufacturing of composite leaf springs}

For injection molding of the leaf spring, the chosen leaf spring materials; unreinforced polyester, $20 \%$ brief carbon fiber strengthened polyester and 20\% long carbon fiber strengthened polyester have been used. To start with, for two hours unreinforced substances have been preheated at $90^{\circ} \mathrm{C}$ and screw rotation of $70 \mathrm{rpm}$ and a low backpressure of $0.30 \mathrm{MPa}$ was saved to lessen the harm of residual fiber duration all through molding.

\subsection{Experimental procedure}

\subsubsection{Static performance evaluation of springs}

Relative value of elastic and viscous additives relies upon on how fast the aspect is deformed. to differentiate the time - based load - deflection conduct, composite leaf springs have been subjected to strain prices of 3,5,10 and $60 \mathrm{~mm}$ min-1. To quantify behavior of molded leaf spring, molded leaf springs have been subjected to loading value of 7, 14 and $25 \mathrm{~N} / \mathrm{s}$ and the corresponding load deflection curve for loading and unloading were additionally designed. beneath service condition, the damping behavior of molded composite leaf spring became exhibited through a place enclosed via the loading and unloading curve. To study the burden relaxation characteristics at the molded leaf spring, molded leaf springs had been subjected to a maximum deflection of $14 \mathrm{~mm}$ and the deflection become maintained constantly for a time period.

\subsubsection{Load and Deflection Performance of the Composite Springs}

Energy as well as deflection determines the design of suspension leaf spring. the weight-deflection curve of the molded lengthy fiber strengthened leaf spring (LFS), short fiber reinforced leaf spring (SFS) and unreinforced leaf spring (UFS). The load capability for a deflection of $14 \mathrm{~mm}$ for SFS, LFS and US are 570, 188 and $95 \mathrm{~N}$ respectively is determined from the Figure 1. From the opening portion of the burden-deflection curve, the spring rate of lengthy, short carbon fiber reinforced leaf spring and unreinforced leaf spring have been computed and determined to be 22.32 , 48.7 and $12.4 \mathrm{~N} / \mathrm{mm}$ respectively.

Spring price of LFS became discovered to be about 3 instances more than that of SFS and five times extra than UFS. whilst the checks had been carried beneath regular displacement rate of $7 \mathrm{~mm} / \mathrm{min}$, it is to be eminent that the above behaviour changed into discovered vividly. Suspension

Table 1. Composition and mechanical Properties of unreinforced and reinforced polyester composites

\begin{tabular}{|c|c|c|c|}
\hline \multirow[b]{2}{*}{ Properties } & \multicolumn{3}{|c|}{ Composition of Materials } \\
\hline & $\begin{array}{c}\text { Unreinforced polyester } \\
\text { (UFPE) }\end{array}$ & $\begin{array}{c}\text { Short carbon } \\
\text { fiber + polyester } \\
\text { (SF+PE) }\end{array}$ & $\begin{array}{c}\text { Long carbon } \\
\text { fiber + polyester } \\
(\mathrm{LF}+\mathrm{PE}) \\
\end{array}$ \\
\hline \multirow[t]{2}{*}{ Fiber fraction( $\%$ by weight $)$} & 100 & $20+80$ & $20+80$ \\
\hline & \multicolumn{3}{|c|}{ Mechanical Properties } \\
\hline Ultimate strength $\left(\mathrm{N} / \mathrm{mm}^{2}\right)$ & 34 & 75 & 128 \\
\hline Modulus of elasticity $\left(\mathrm{N} / \mathrm{mm}^{2}\right)$ & 1750 & 3450 & 5700 \\
\hline Density $\left(\mathrm{kg} / \mathrm{mm}^{3}\right)$ & 0.925 & 1.12 & 1.1 \\
\hline
\end{tabular}




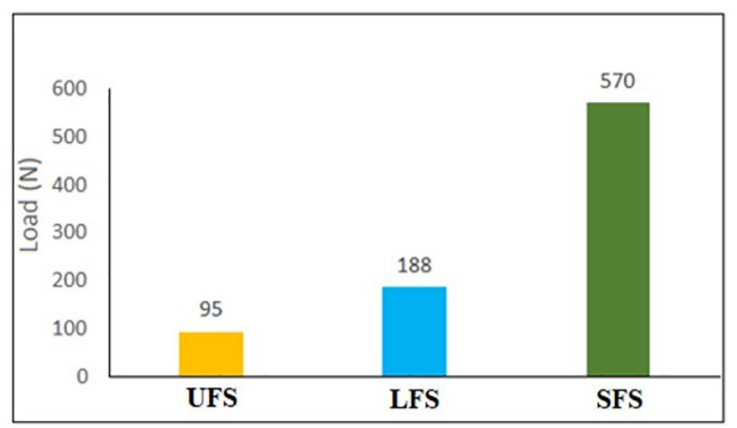

Figure 1. Load capability of carbon fiber reinforced and unreinforced fibers

leaf springs had been subjected to the time various load, due to the vehicle service circumstance, and thus there is a necessity to comprehend the weight - deflection behavior of moulded leaf springs at diverse stress rates.

\subsubsection{Strain Rate of the Spring}

Due to viscoelastic characteristics of the base polymeric material, thermoplastic composite material properties are time reliant. The strain rate of LFS, SFS and UFS is delineated inside the Figure 2. The displacement rates; 3, 5, 10 and $60 \mathrm{~mm} / \mathrm{min}$ had been considered inside the present examination. Load required for the layout deflection of 14 $\mathrm{mm}$ will increase with the increase in displacement rate for the taken into consideration leaf springs. however, because of the decline in matrix ductility due to fiber reinforcement, stress fee sensitivity of strengthened leaf springs became determined to be much less than unreinforced leaf springs which is confirmed from the reduction in stress as reported in tensile test. The degree of viscous component is polymeric material's ductility and the pressure rate sensitivity is proportional to the viscous issue of the material. greater load carrying ability is precipitated while the pressure rate will increase, the viscous thing is reduced. better the energy absorbed, better is the isolation of a automobile from vibration on account that electricity is absorbed within the leaf springs. thus, it's miles crucial to recognize the energy storage capacity of the moulded leaf springs.

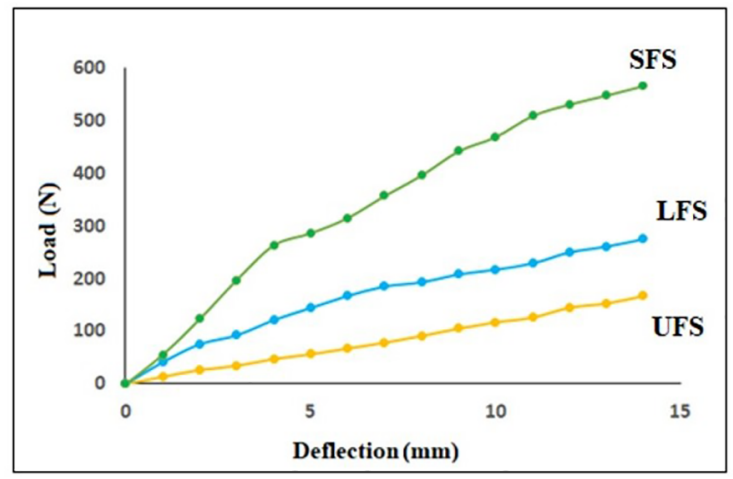

Figure 2. Strain rate of the composite springs

\subsubsection{Energy Storage ability of the Composite Springs}

In carrier, to avoid premature failure, spring pressure ought to no longer surpass permissible strain. the quantity of power is confined with the aid of this attention and which can be saved inside the spring. For a maximum designed deflection of $14 \mathrm{~mm}$, the engrossed strength for the effective work executed became expected by way of calculating the region below load-deflection curve. LFS can keep more power than other two selected leaf springs (UFS, SFS) and these exceptional enables to offer better vehicle riding comfort and electricity stored by the selected UFS, SFS and LFS were 9.7, 29 and 21.5 J.

For the molded leaf spring material, with the variation in pressure rate, the power storage potential additionally differs and it increases with pressure price.

The energy absorbing behavior of UFS and SFS are touchy to the stress charge than that of LFS is showed from the Figure 3. The performance of leaf spring is appreciably encouraged by means of the damping conduct of leaf spring cloth; consequently, it's miles essential to comprehend the damping conduct of moulded leaf springs.

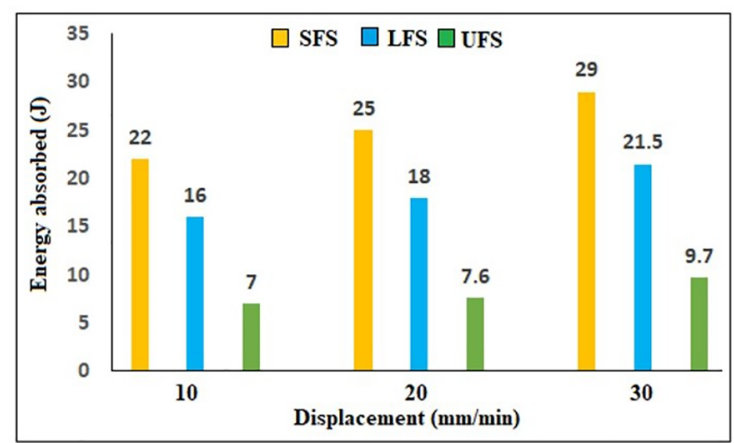

Figure 3. Energy absorbing behavior of composite springs

\subsubsection{Performance of Composite Springs}

Thecorrect principle for anawesome vehicle experience is excessive material damping aspect of a composite material provide first rate noise and vibration diminution ${ }^{5}$. throughout mechanical deformation, huge amount of inner friction within the cloth is generated through the visco- elastic traits of polymer substances. For a given extent fraction of carbon fiber fabric, similar observations in the long and quick fiber reinforced polyamide composite, wherein the fracture surface exposed that longer fiber duration had significantly slighter fiber density in keeping with unit vicinity than that of quick fiber polyamide composite. through the fiber-matrix interface energy is dissipated. as a result, electricity dissipation is greater than that of LFS substances with the presence of greater fiber results in SFS material. Performance of reinforced and unreinforced springs as shown in Figure 4. 


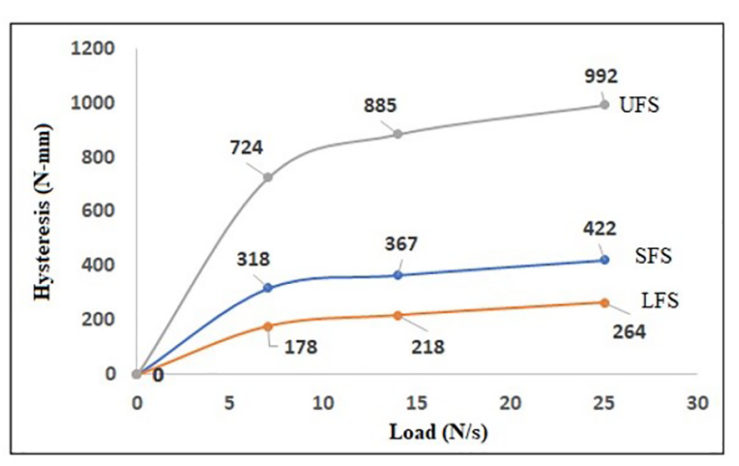

Figure 4. Performance of reinforced and unreinforced springs

\section{Fatigue Behaviour Evaluation Methodology}

For the fatigue performance assessment, UFS, $20 \mathrm{wt} \%$ , SFS and $20 \mathrm{wt} \%$ LFS had been used. As Fmax (maximum load), the weight taken for this significance of deflection of test leaf spring was considered. checks were finished below pulsating bending mode with an amplitude ratio $\mathrm{A}=-1$ due to the fact leaf springs are not subjected to completely reversed load in service. Molded test leaf springs had been subjected to different degrees of alternating loads in regards to Fmax at a frequency of $0.5 \mathrm{~Hz}$. assessments had been executed under laboratory situations. With the assist of cyclic loaddeflection curve, leaf spring harm changed into constantly monitored for the duration of fatigue check.

To quantify energy dissipation and spring charge drop, the cyclic load-deflection plot at 0.9 Pmax, 0.95 Fmax and Fmax changed into further employed. while the spring rate became decreased by way of $8 \%$ or fracture, the failure of springs changed into taken under consideration. The effect of fiber length as shown in Figure 5.

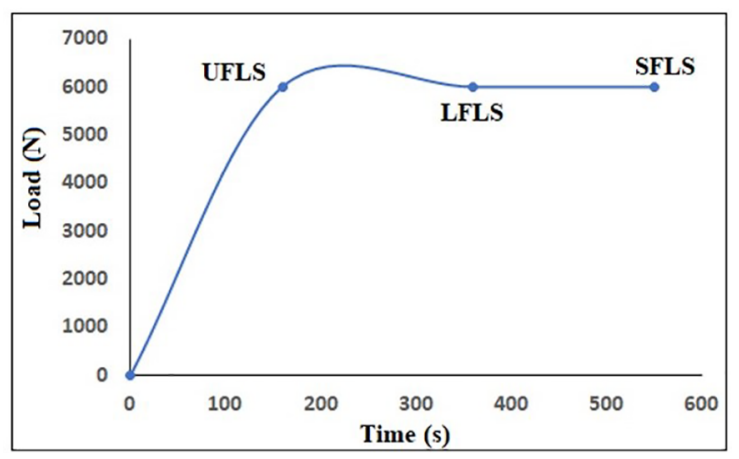

Figure 5. Effect of fiber length on load Vs Time.

\subsection{Fatigue Performance of the Springs}

\subsubsection{Energy dissipation of the springs}

The passengers driving consolation is appreciably inspired by way of energy depravity behavior of a suspension system. energy depravity significantly reduces the spring rate which isn>t always appropriate for suspension utility although it reduces structural vibration. Energy depravity ratio is the ratio of energy misplaced/cycle (measured from the location enclosed via the loading-unloading curve) to the stress energy/ cycle (location enclosed with the aid of the loading curve). As a hallmark, energy depravity ratio parameter was used for the fatigue overall performance assessment ${ }^{30}$. energy depravity ratio as a measure of damping was distinct and the instant increase in the damping for valve spring retainer underneath fatigue conditions was also quantified. ${ }^{31}$.

Fatigue life of SFS, LFS and UFS ranged from 305-2,00,000 cycles, 280-2,00,000 cycles and 260-2,00,000 cycles respectively. general period to complete one path for SFS, LFS and UFS was 364,288 and 229 hours respectively and the overall quantity of records (load-deflection) collected consistent with cycle became eight. The total number of load, in addition to deflection facts corresponding to SFS for one trail is 40,45,124. Likewise, general numbers of statistics corresponding to LFS and UFS for one path are 31,16,181 and 28,41,917 respectively. For continuous monitoring of damage brought on in the test leaf springs. The fatique load and deflection of composite spring as shown in the Figure 6. A deliberation turned into exemplified for a loading level of Pmax although fatigue performance assessment is completed at a spread of loading stages. From the static take a look at, Pmax for UFS, LFS and SFS are 186, 257 and $623 \mathrm{~N}$ obtained respectively. The cyclic load deflection plot is acquired at various levels of fatigue life viz. $0.1,10,50$ and $100 \% \mathrm{~N}_{\mathrm{f}}$, in which $\mathrm{N}_{\mathrm{f}}$ is the overall quantity of cycles prior to failure.

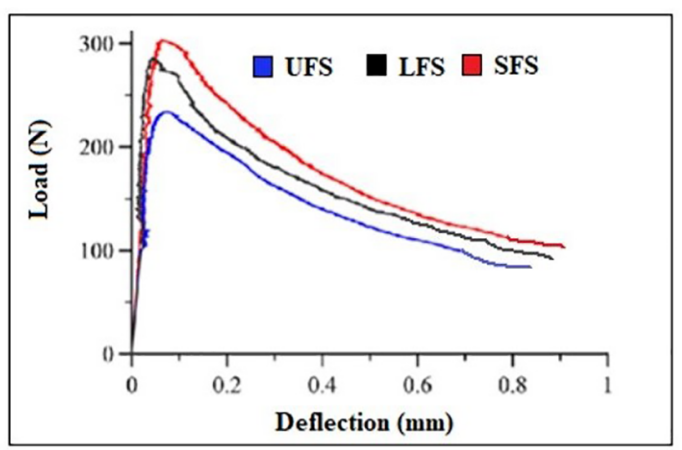

Figure 6. Fatigue load and deflection of composite spring

From the cyclic load-deflection plot, energy dissipation of check leaf spring is classified. The energy depravity ratio at the start (10th) and after finite range of cycle (4200th) become computed with a purpose to examine the leaf spring overall performance. The increases in electricity depravity ratio from the start to 4200th cycle for UFS, LFS and SFS have found to be 1.53,1.37 and 1.13 respectively. This conduct is owing to the presence of greater fiber ends in SFS than that of LFS. moreover, the energy dissipation appreciably is decreased via the presence of excessive modulus lengthy carbon fiber. The decreased power dissipation conduct as a result of the presence of excessive modulus carbon fiber inside the composite springs become said ${ }^{23}$. 
The cyclic load-deflection curve of lengthy fiber reinforced leaf springs subjected to 0.75 Fmax , 1 Fmax and 1.4 Fmax at diverse period of fatigue existence $\left(\mathrm{N}_{\mathrm{f}}\right)$ are proven within the Figure 6 at some point of the fatigue loading, full-size increase in deflection with the increase in load is exhibited by the cyclic load-deflection plot of test leaf springs. in addition, quantification of spring charge is of the practical importance to the suspension application considering that energy depravity is connected with the spring rate reduction.

\subsubsection{Fatigue Strength of composite leaf springs}

Endurance restriction of the tested thermoplastic composite spring is taken as $2 \times 10^{6}$ cycles and the run out specimens turned into indicated by way of the arrow marks. The brought about leaf spring bending strain $\mathrm{S}_{\mathrm{b}}$ is computed using equation 1 . the similar equation for designing the mono composite leaf spring for depicting the leaf spring bending pressure estimation changed into implemented.

$$
S_{b}=\frac{3 P L_{e}}{2 b_{c} t^{2}}
$$

where, $\mathrm{P}$ is the applied load, $\mathrm{L}_{\mathrm{e}}$ is effective length of the spring, $b_{c}$ is the width at the center and $t$ is the beam thickness at center. Test conditions were repeated for three times, and the whole set of data irrespective of load levels were used. A linear interpolation on the semi logarithmic $\operatorname{plot}\left(\mathrm{S}_{\max }-\log \left(\mathrm{N}_{\mathrm{f}}\right)\right)$ was performed and the equation for the linear interpolation takes the form

$$
S_{\max }=S_{o}-B \log \left(N_{f}\right)
$$

This equation is rewritten as

$$
S_{\max } / S_{o}=1-m \log \left(N_{f}\right)
$$

where, $\mathrm{S}_{\max }$ is the maximum bending stress, $\mathrm{S}_{\mathrm{o}}$ is the static strength and $\mathrm{m}$ is a constant parameter representing the fatigue sensitivity of material. The fatigue stress and life of reinforced and unreinforced leaf springs as shown in Figure 7. The standards of correlation index have been fine in the regulations. Linear interpolation changed into finished the use of the above equation 3 on the semi-logarithmic plot by using diverse authors. better fatigue resistance in both the low and excessive cycle fatigue became possessed by using SFS. due to the improved load switch from the fiber to matrix, fatigue performance of leaf springs was observed to be more advantageous with the boom in fiber period. Higher sensitivity towards stress level than that of LFS and UFS was showed by SFS. The reduced ductility of the matrix is caused the sensitiveness toward stress level ${ }^{32-34}$.

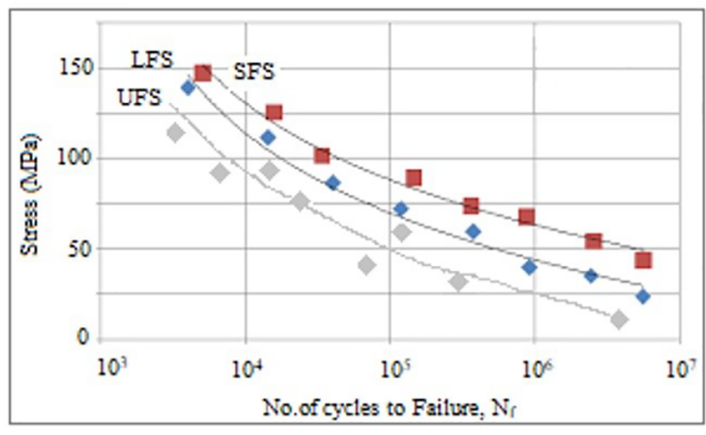

Figure 7. Fatigue stress and life of reinforced and unreinforced springs

UFS and SFS exhibited the drop in spring rate and LFS exhibited fracture for all the taken into consideration masses. The fractured surface of the LF and SF at distinct loading conditions is shown in Figures $8(a-b)$, wherein two distinct failure capabilities are observed. Figure $8(a-b)$ correspond to the composite spring segment which reports tensile stresses and for this reason micro ductile/matrix fibrillation turned into determined.

Figure 9. (a) and (b) represents the SEM image of $25 \mathrm{~N}$ indicating SFS and $25 \mathrm{~N}$ indicating LFS respectively. The micro ductile failure feature which corresponds to the tensile stress region of LFS leaf spring is pointed out within the SEM Figure 9 (a) and the brittle failure characteristic which corresponds to the compressive strain location of LFS leaf spring is indicated in SEM Figure 9 (b).

In Figure 10. represents the fractured surface of the short carbon firber reinforced polyester. The fiber orientation is depended by way of the fatigue strength of discontinuous fiber reinforced part appreciably which in turn depends specially on the part form and gate role inside the moulding die. the majority of the discontinuous fiber orient along the length of the leaf spring for the reason that gate role become kept in this
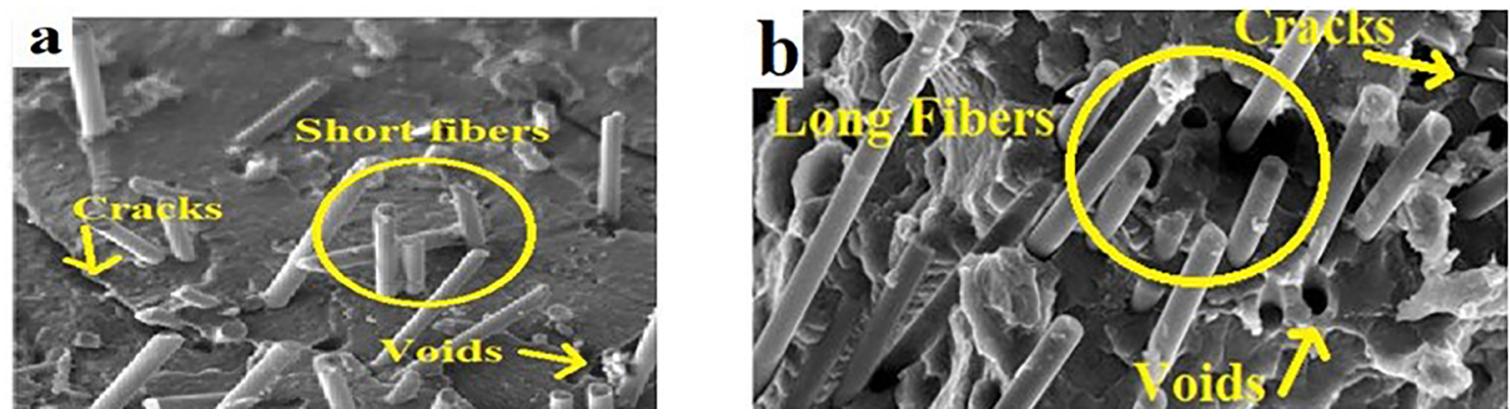

Figure 8. (a) SEM for ductile fracture of Short fibers at $14 \mathrm{~N}$ and (b) Long fibers at $14 \mathrm{~N}$ 

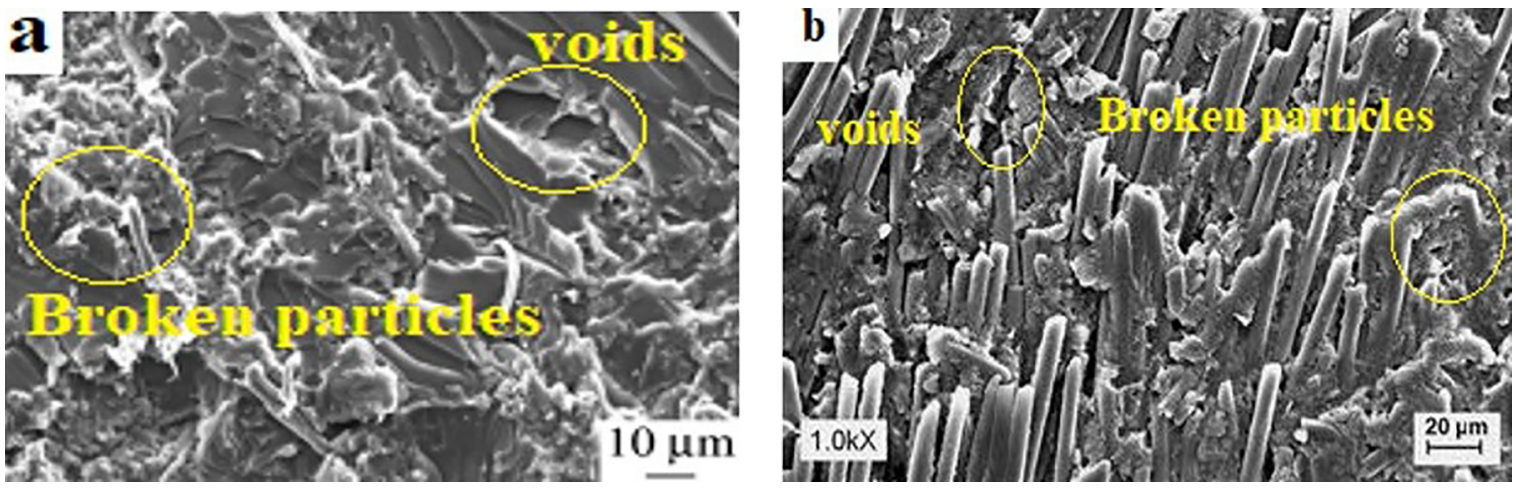

Figure 9. (a) SEM image of $25 \mathrm{~N}$ indicating SFS and (b) $25 \mathrm{~N}$ indicating LFS

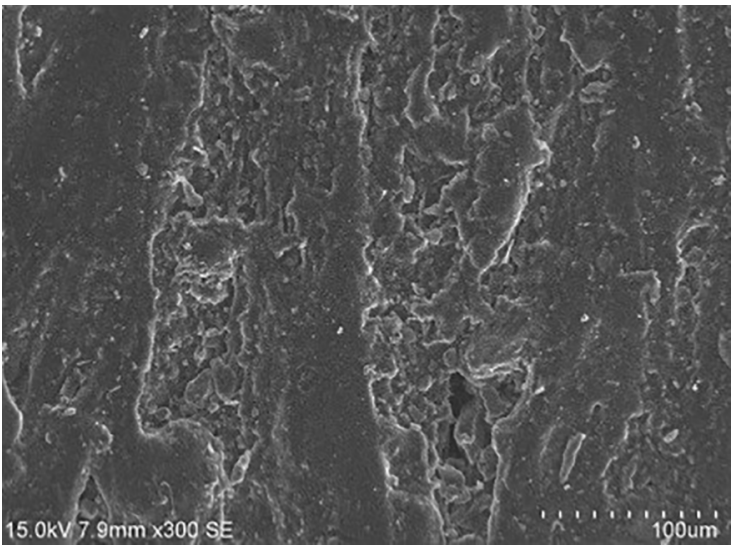

Figure 10. Image of the fractured surface of short carbon fiber reinforced polyester

type of manner. Figure 10 indicates the fiber orientation using mould go with the flow polyseter insight for the moulded leaf spring where fiber turned into orientated alongside the leaf spring period, that is preferred for load carrying application because the load is appearing ordinary to the fiber direction.

\section{Conclusions}

Static and fatigue performances of carbon fiber thermoplastic strengthened composite spring become experimentally investigated and following conclusions have been made:

The spring rate of LFS become located to be about three instances extra than that of SFS and 5 instances greater than UFS. Energy storage functionality of LFS turned into located to be considerably better than that of SFS and UFS, which enables to segregate vibrations. Load-deflection behavior of LFS confirmed much less strain price sensitiveness than that of SFS and UFS.

Fatigue overall performance of injection moulded thermoplastic composite leaf springs under pulsating compression mode turned into investigated at numerous alternating loading ranges, in which overall performance of leaf spring became determined to be more advantageous with the fiber period.
Quick fiber reinforced and unreinforced polyester leaf springs exhibited $10 \%$ drop in spring rate, however long carbon fiber strengthened polyester leaf spring exhibited fracture failure on the tensile surface.

These composite springs can be useful for low load carrying vehicles in automobile applications.

\section{References}

1. Beardmore P. Composite structures for automobiles. Composite Structures. 1986;5(3):163-76.

2. Morris CJ. Composite integrated rear suspension. Composite Structures. 1986;5(3):233-42.

3. Sancaktar E, Gratton M. Design analysis and optimization of composite leaf springs for light vehicle applications. Composite Structures. 1999;44(2-3):195-204.

4. Rajendran I, Vijayarangan S. Optimal design of a composite leaf spring using genetic algorithms. International Journal of Computers and Structures. 2001;79:1121-29.

5. Hou JP, Cherruault JYA, Jeronimidis G, Mayer R. Design, testing and simulation of fiber composite leaf springs for heavy axle load. The Journal of Strain Analysis for Engineering Design. 2005;40(6):497-504.

6. Mallick PK. Composites engineering handbook. New York: CRC Press Book; 1997.

7. Crawford RJ. Plastics engineering. $3^{\text {rd }}$ ed. Oxford: ButterworthHeinemann; 1998.

8. Beardmore P, Johnson CF. The potential for composites in structural automotive applications. Composite Science and Technology. 1986;26(4):251-81.

9. Markarian J. Long fiber reinforcement drives automotive market forward. Plastics, Additives and Compounding. 2005;7(3):24-9.

10. Thomason JL. The influence of fiber length and concentration on the properties of glass fiber reinforced polypropylene: 5 . Injection moulded long and short fiber PP. Composites Part A: Applied Science and Manufacturing. 2002;33(12):1641-52.

11. Zhang H, Zhang Z, Friedrich K. Effect of fiber length on the wear resistance of short carbon fiber reinforced epoxy composites. Composites Science and Technology. 2006;67:222-30. 
12. Mathew MT, Padaki V, Rocha LA, Gomes JR, Alagirusamy R, Deopura BL, Fangueiro R. Tribological properties of the directionally oriented warp knit GFRP composites. Wear. 2007;263:930-8.

13. Mathew MT, Padaki NV, Alagirusamy R, Deopura BL, Fangueiro R, Rocha LA, et al. Tribological behaviour of multilayered textile composites: the effect of reciprocating sliding frequency. Wear. 2009;267:26-33.

14. Al-Qureshi HA. Automobile leaf springs from composite materials. Journal of Materials Processing Technology. 2001;118(1-3):58-61.

15. Lo KH, McCusker JJ, Gottenberg WG. Composite leaf spring for tank trailer suspensions. Journal of Reinforced Plastics and Composites. 1987;6(1):100-12.

16. Subramanian C, Senthilvelan S. Development and preliminary performance evaluation of discontinuous fiber reinforced thermoplastic leaf spring. Journal of Materials: Design and Applications. 2009;223(3):131-42.

17. Kretsis G, Matthews FL. The strength of bolted joints in glass fiber/epoxy laminates. Composites. 1985;16(2):92-102.

18. Aktas A, Imrek H, Cunedioglu Y. Experimental and numerical failure analysis of pinned-joints in composite materials. Composite Structure. 2009;89(3):459-66.

19. Collings TA. The strength of bolted joints in multi-directional CFRP laminates. Composites. 1977;8:46-54.

20. Stockdale JH, Matthews FL. The effect of clamping pressure on bolt bearing loads in glass fiber reinforced plastics. Composites. 1976;7:34-8.

21. Cooper C, Turvey GJ. Effects of joint geometry and bolt torque on the structural performance of single bolt tension joints in pultruded GRP sheet material. Composite Structure. 1995;32(1-4):217-26.

22. McCarthy CT, McCarthy MA, Lawlor VP. Progressive damage analysis of multibolt composite joints with variable bolt-hole clearances. Composites Part B: Engineering. 2005;36(4):290-305.

23. Crews Junior J. Bolt-bearing fatigue of a graphitelepoxy laminate. Philadelphia, PA: American Society for Testing and Materials - ASTM; 1981. p. 131-44.
24. Chen HS. The static and fatigue strength of bolted joints in composites with hygrothermal cycling. Composite Structure. 2001;52(3-4):295-306.

25. Pinnell MF. An examination of the effect of composite constituent properties on the notched strength performance of composite materials. Composites Science and Technology. 1996;56(12):1405-13.

26. Swanson SR, Cairns DS, Guyll ME, Johnson D. Compression fatigue response for carbon fiber with conventional and toughened epoxy matrices with damage. Journal of Engineering Materials and Technology. 1993;115(1):116-21.

27. Carlsson LA, Aronsson CG, Backlund J. Notch sensitivity of thermoset and thermoplastic laminates loaded in tension. Journal of Materials Science. 1989;24:1670-82.

28. Ferreira JAM, Costa JDM, Richardson MOW. Effect of notch and test conditions on the fatigue of a glass-fiber-reinforced polypropylene composite. Composites Science and Technology. 1997;57(9-10):1243-8.

29. Twintex Product Data Sheet. Long fiber thermoplastic pellets. USA: Saint Gobain Vetrotex America Inc.; 2005.

30. Sugimoto T, Sasaki Y, Yamasaki M. Fatigue of structural plywood under cyclic shear through thickness I: fatigue process and failure criterion based on strain energy. Journal of Wood Science. 2007;53(4):296-302.

31. Orth F, Hoffmann L, Zilch-Bremer H, Ehrenstein GW. Evaluation of composites under dynamic load. Composite Structures. 1993;24(3):265-72.

32. Kumar SS, Kanagaraj G. Investigation of characterization and mechanical performances of $\mathrm{Al}_{2} \mathrm{O}_{3}$ and $\mathrm{SiC}$ reinforced $\mathrm{PA} 6$ hybrid composites. Journal of Inorganic and Organometallic Polymers and Material. 2016;26(4):788-98.

33. Kumar SS, Kanagaraj G. Evaluation of mechanical properties and characterization of silicon carbide-reinforced polyamide 6 polymer composites and their engineering applications. International Journal of Polymer Analysis and Characterization. 2016;21(5):378-86.

34. Kumar SS, Kanagaraj G. Experimental investigation on tribological behaviours of PA6, PA6-reinforced $\mathrm{Al}_{2} \mathrm{O}_{3}$ and PA6-reinforced graphite polymer composites. Bulletin of Materials Science. 2016;39(6):1467-81 